\title{
SEGMENTAL CLAVICLE FRACTURE
}

\section{ABSTRACT}

The aim here was to present an unusual case of segmental clavicle fracture associated with ipsilateral rib fracture. Although the

clavicle is very superficial, undetected cases of both types of fracture may occur, because these patients usually suffer

\section{INTRODUCTION}

Among clavicle fractures, $69 \%$ occur in the diaphysis, $28 \%$ in the lateral extremity and $3 \%$ in the medial portion ${ }^{(1)}$. Meanwhile, segmental fractures are very rare, with few articles described in English literature. Clavicle fractures usually have a very easy diagnosis as their anatomical position is very superficial, and their consolidation is achieved even without treatment in most cases. But in spite of this characteristic, many complications can occur, including ipsilateral rib fracture ${ }^{(2)}$. They occur less often after direct trauma, and this has been the mechanism described in segmental fractures in which there is generally multiple trauma in the clavicle ${ }^{(3)}$.

In segmental fractures, the fractured segment suffers the action of muscular forces and may evolve with blood supply failure, for which reason fixation should be performed early ${ }^{(3,4)}$.

Allman $^{(5)}$, in 1967, was the first to classify fractures dividing the clavicle anatomically into three segments. Other modifications were made, and finally with more details, by $\mathrm{Craig}^{(6)}$ in 1991.

The purpose of this study is to present a rare fracture of the clavicle not yet published in indexed Brazilian literature. multiple trauma. The case of a patient with a fracture of the diaphysis and lateral extremity of the clavicle is described: the patient was treated surgically and an excellent result was achieved. Similar cases in the literature are reviewed and their management is discussed.

Keywords - Clavicle; Fractures Fixation; Orthopedic Surgery

\section{CASE REPORT}

Male patient, age 41, who fell from a roof and was treated for vomiting, left otorrhagia, cranioencephalic trauma, nosebleed, segmental fracture of the left clavicle and fracture of the third left posterior rib. He required treatment in an intensive care unit, and after clinical and neurological improvement was released to the orthopedic department. He did not present neurovascular deficit in the shoulder girdle due to the clavicle fractures, or pneumothorax due to the rib fracture, but evolved with left anacusis. Clinically, there was gross deformity in the middle third of the clavicle (Figure 1), the only site about which the patient complained; and, radiologically, there was deviation of the lateral extremity and greater than 2 $\mathrm{cm}$ of the diaphyseal fracture (Figures 2A and 2B). The fractures were classified in group I (diaphysis), and the lateral fracture in group II, as Craig type II B fractures (Figure 3). Radiographs were taken in two views in plain neutral AP and with $45^{\circ}$ cephalic tilt to classify and decide on the treatment.

Osteosynthesis of the diaphyseal fracture was executed after clinical clearance using a reconstruction plate molded above the clavicle and two Kirschner wires crossed at the distal extremity (Figure 3 ). The wires were removed after seven weeks and the patient

1 - Orthopedist and Traumatologist of Fundação São Francisco Xavier/Hospital Márcio Cunha - Ipatinga, MG.

Study conducted at Fundação São Francisco Xavier/Hospital Márcio Cunha - Ipatinga, MG.

Mailing address: Av. Itália, 2.556, Bairro Cariru - 35160115 - Ipatinga, MG. Emails: ovazadao@yahoo.com.br and evander.grossi@usiminas.com Study received for publication: 3/15/2011, accepted for publication: 6/16/2011 
was referred to physiotherapy. After 14 weeks, he returned with the fractures consolidated (Figures 4A and 4B), asymptomatic, and with mobility preserved. The plate was removed after seven months due to protrusion and discomfort.

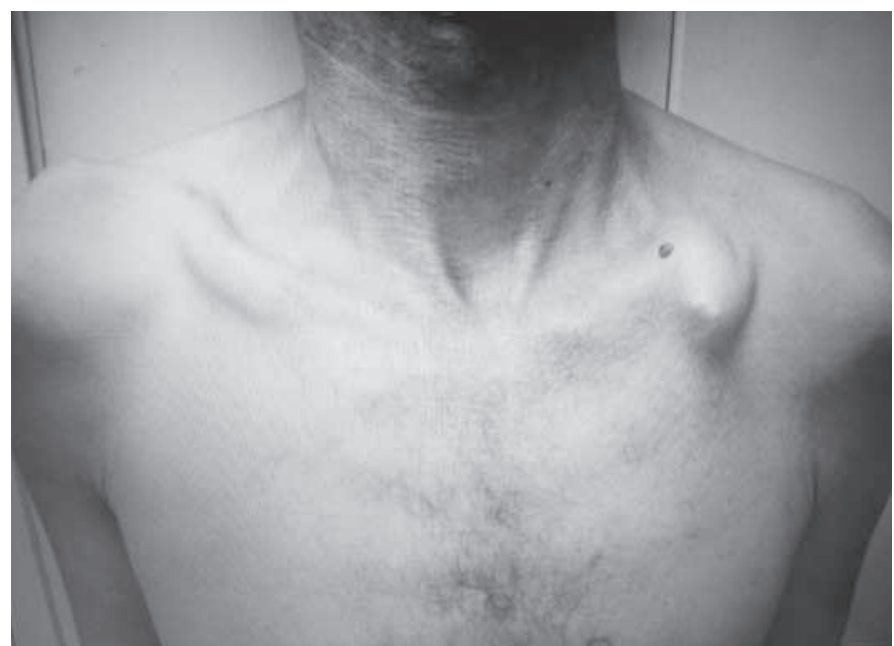

Figure 1 - Clinical aspect of the gross deformity of the diaphyseal fracture of the left clavicle.
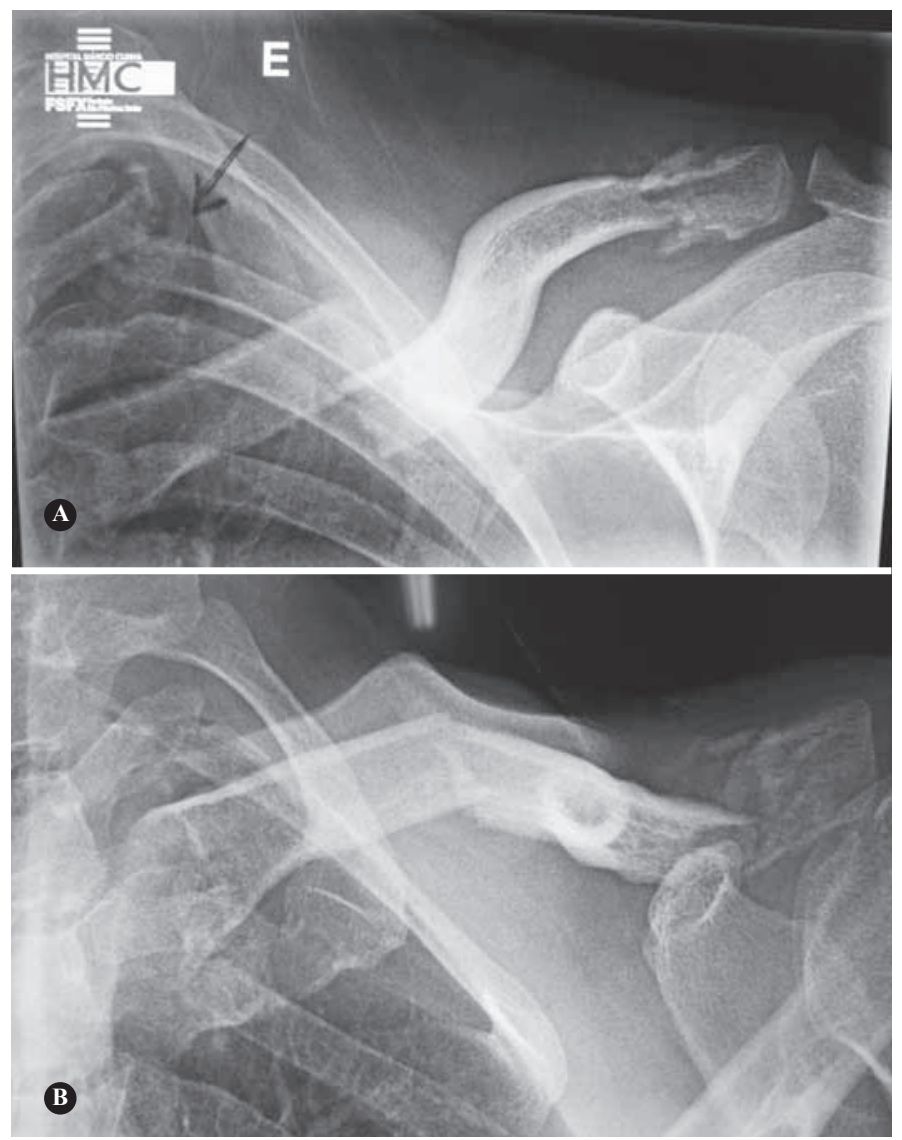

Figure 2 - (A) Segmental clavicle fracture showing deviation of the diaphyseal fracture and alignment of the lateral fracture. Arrow showing the rib fracture. (B) Aligned fracture of the diaphysis and with deviation of the lateral extremity.

\section{DISCUSSION}

Osman $e t a l^{(2)}$ treated a similar case of fracture of the diaphysis and lateral third of the clavicle, which was associated with ipsilateral rib fractures and consequent pneumothorax. The patient underwent plate

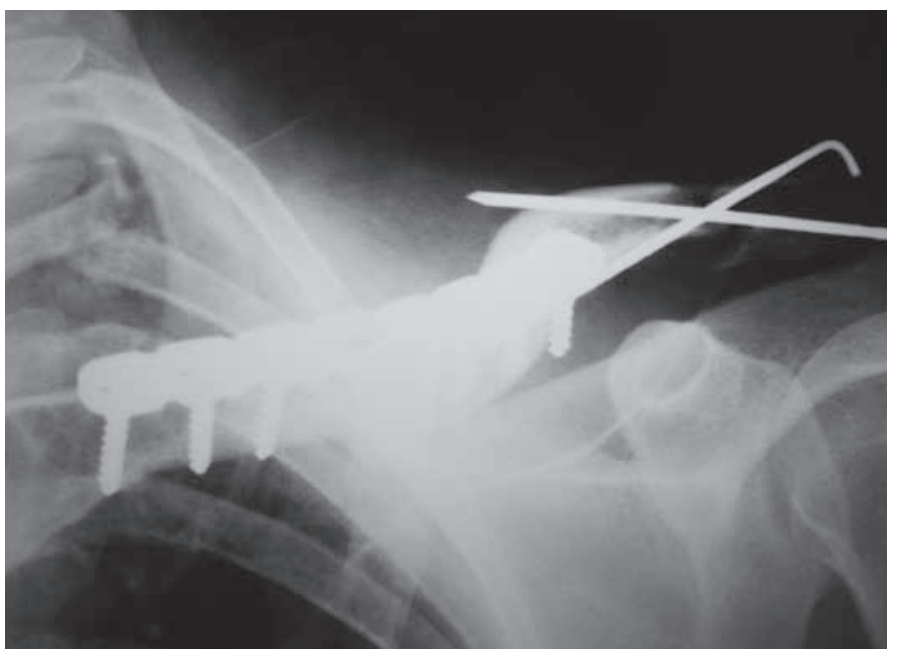

Figure 3 - Immediate postoperative period showing the osteosyntheses with plate and wires.

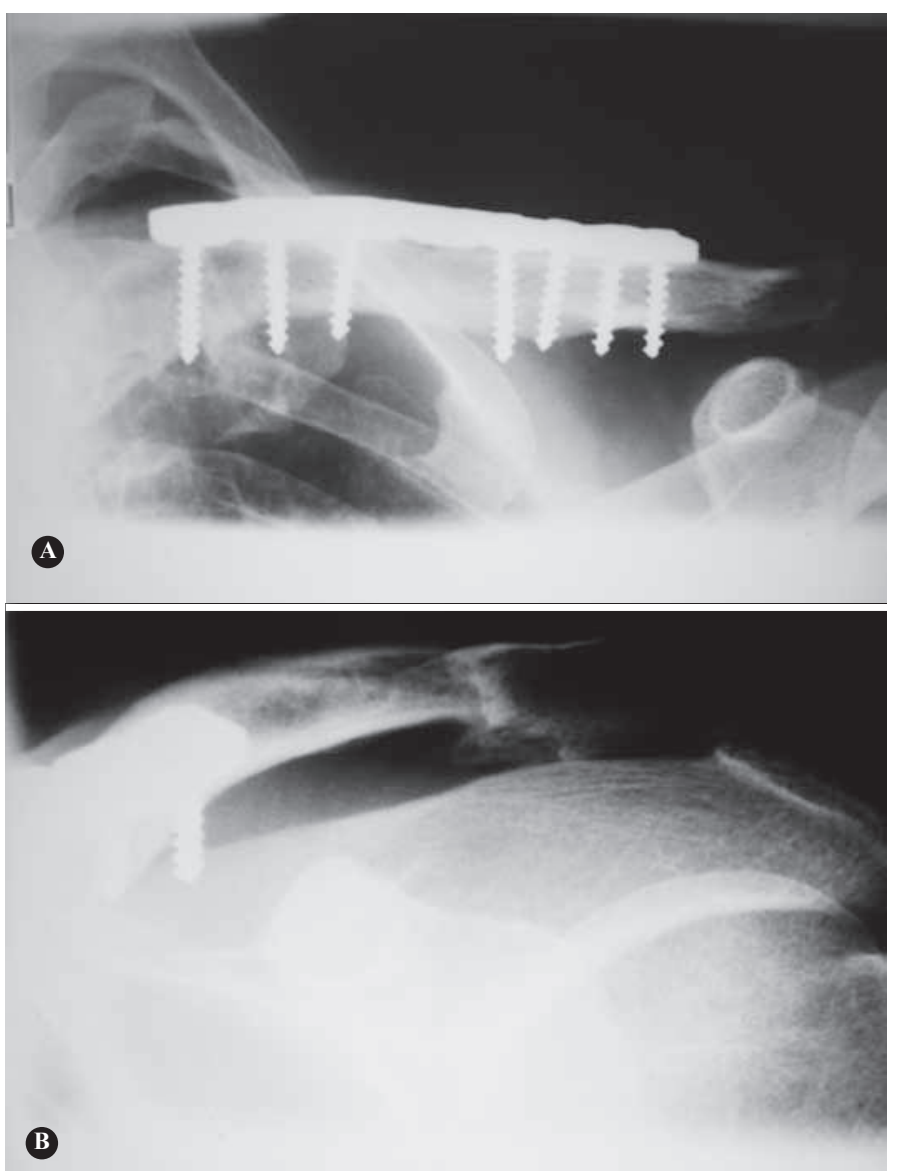

Figure 4 - (A) Conventional radiography for evaluation of the diaphyseal fracture. (B) Conventional radiography for evaluation of the lateral fracture. 
osteosynthesis with subsequent removal of the plates since one of the screws caused an impact in the coracoid process, and also due to the risk of fracture between the plates. Our patient's second-rib fracture did not cause pneumopathy.

Miller $e t a l^{(7)}$ presented a report of fracture of the medial and lateral extremity of the clavicle with the use of a reconstruction plate and another with locking T-plate, and Karimi et $a l^{(8)}$ had a case similar to ours that was also treated by the same method; both authors emphasized that due to the rarity of the case, there is no routine surgical technique described for the treatment of this type of fracture.

Osteosynthesis of diaphyseal clavicle fractures with locked plates is an excellent treatment option, and some authors ${ }^{(2,4)}$ have treated segmental fractures similar to this one using this method. But in our case, such an implant is not available for use in patients of the public health network.

We agree with the indication of osteosynthesis in this type of fracture due to the risk of pseudarthrosis, according to Heywood and Clasper ${ }^{(4)}$, who treated segmental clavicle fracture with a superior plate and use of the hook plate, but the latter is seldom used in our circles.

The choice of plates as diaphyseal clavicle fracture synthesis material is more common, and their anterior placement is more aesthetic, while the superior placement has the advantage of greater rigidity ${ }^{(9,10)}$, yet they increase the risks of neurovascular lesion and prominence of the plate, a fact that was observed in our patient. The intramedullary method has also been used in diaphyseal fractures, through threaded, smooth wires, locked mobile nails and cannulated screws; but in the case of segmental fracture, the "S"

\section{REFERENCES}

1. Robinson CM. Fractures of the clavicle in the adult. Epidemiology and classification. J Bone Joint Surg Br. 1998;80(3):476-84.

2. Osman N, Sinopidis C, Gibson L Unusual segmental fracture of clavicle associated with rib fractures and pneumothorax. J Orthop Surg. 2010;15(2). Disponível em: http://www.ispub.com/journal/the_internet_journal_of_orthopedic_surgery/volume_15_number_2_2/article/unusual-segmental-fracture-of-theclavicle-associated-with-rib-fractures-and-pneumothorax.html

3. Singh B, Singh S, Saraf N, Farooque K, Sharma V. Unusual Mechanism of Injury with Segmental Fracture Clavicle. J Orthop Surg. 2007;6(1). Disponivel em: http://www.ispub.com/journal/the_internet_journal_of_orthopedic_surgery/ volume 15 number_2 2/article/unusual-segmental-fracture-of-the-clavicleassociated-with-rib-fractures-and-pneumothorax.html

4. Heywood R, Clasper J. An unusual case of segmental clavicle fracture. J R Army Med Corps. 2005;151(2):93-4.

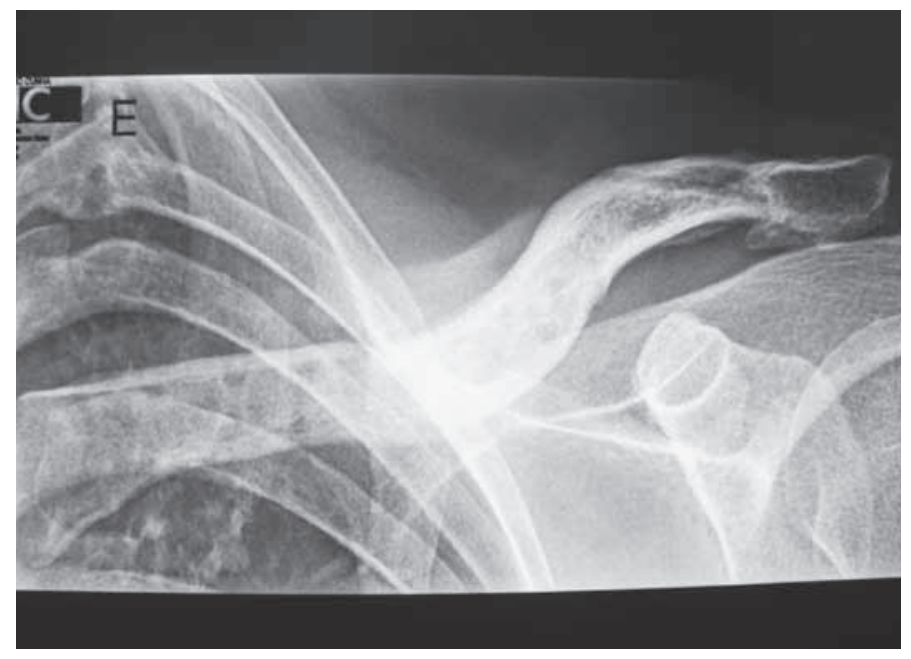

Figure 5 - Digital radiography showing consolidation of fractures after seven months.

shape of the clavicle prevents the same nail from fixing the two fractures with rigidity.

Since many conventional radiographic examinations carried out to diagnose clavicle fracture have good visualization in the diaphysis and to a lesser degree in the lateral extremity, we noticed, during the treatment, that it was necessary to take separate radiographs of these segments to monitor fracture consolidation; yet with digital radiography, it was possible to analyze both fractures in just one view (Figure 5).

\section{CONCLUSION}

Segmental clavicle fractures are rare, but need a good radiological examination of the whole bone in more than one view for diagnosis and treatment, whereas surgical indication ensures a satisfactory result.

5. Allman FL Jr. Fractures and ligamentous injuries of the clavicle and its articulation. J Bone Joint Surg Am. 1967;49(4):774-84.

6. Craig EV. Fractures of the clavicle. In: Rockwood CA Jr, Matsen FA 3rd, editors. The shoulder. Philadelphia: Saunders; 1990. p. 367-412.

7. Miller D, Smith K, Mc Clelland D. Bipolar segmental clavicle fracture. Eur J Orthop Traumatol. 2009;19:337-9.

8. Karimi A, Ettehad H, Akbar MH. Segmental fracture of the clavicle (a very rare case in trauma surgery) Shiraz E-Medical J. 2007;8(2):90-5.

9. lannotti MR, Crosby LA, Stafford P, Grayson G, Goulet R. Effects of plate location and selection on the stability of midshaft clavicle osteotomies: a biomechanical study. J Shoulder Elbow Surg. 2002;11(5):457-62.

10. Celestre P, Roberston C, Mahar A, Oka R, Meunier M, Schwartz A. Biomechanical evaluation of clavicle fracture plating techniques: does a locking plate provide improved stability? J Orthop Trauma. 2008;22(4):241-7. 